\title{
A case report of vanishing testicle: radiological diagnosis and short review
}

\author{
Mohamed Rafi Kathar Hussain * [D
}

\begin{abstract} scrotum reveals the feature of TRS. the least possibility of neoplasm in TRS patients.

\section{Background}

Vanishing testicular syndrome is also known as testicular regression syndrome (TRS) is due to atrophy and disappearance of unilateral testis in the fetal life after the formation of the normal testis. It is a spectrum of disorders; clinical features are depending upon the stage of fetal or early neonatal life at which function of testicles ceases.
\end{abstract}

Background: Vanishing testicular syndrome is also known as testicular regression syndrome (TRS) is due to atrophy and disappearance of testis in the fetal life after the formation of the normal testis. It is a spectrum of disorders; clinical features are depending upon the stage of fetal or early neonatal life at which function of testicles ceases.

Case presentation: Young 40-year-old male patient came for a routine master health checkup. On clinical examination he had a nonpalpable left testis, Rest of the clinical examinations are unremarkable. Referred to ultrasound (USG), for testis localization reveals the absence of left testis in the left scrotal sac and inguinal canal. Further MRI of the

Conclusion: TRS in the 4th-decade adult is rarely reported in the literature. The asymptomatic presentation shows

Keywords: Vanishing testis, USG, Cryptorchidism, Testicular regression syndrome

\section{Case presentation}

Young 40-year-old male patient came to the hospital for a routine master health checkup. No significant past surgical or medical history. He is married 10 years before and had two children. His vital parameters were stable. Examinations of the respiratory, cardiovascular system, central

*Correspondence: radiologistrafi1984@gmail.com

Department of Radio Diagnosis, Sri Manukulavinyagar Medical College, Kalitheerthalkuppam, Puducherry, India nervous system are within normal limits. The abdomen was soft with no organomegaly. Local examination of the scrotum shows nonpalpable left testis. The right testis appears normal. The patient was referred to USG. USG shows normal right testis with normal echoes and vascularity (Fig. 1). The left scrotal sac is empty. The left testis is not visualized in the left scrotal sac and the left inguinal canal. The patient was further subjected to MRI to find the left testis. MRI shows a normal appearance of the right testis. Left spermatic cord structures are noted within the left inguinal canal. A small soft tissue nodule was noted in the tip of the left spermatic cord (Figs. 2, 3, $4,5)$.

Left testis is not separately visualized in the left scrotum, inguinal canal, or pelvis. Features are suggestive of left TRS. The patient is not willing for surgical exploration and was advised to have a follow-up.

\section{Discussion}

Vanishing testicular syndrome is also known as testicular regression syndrome (TRS) is due to atrophy and disappearance of unilateral testis in the fetal life 


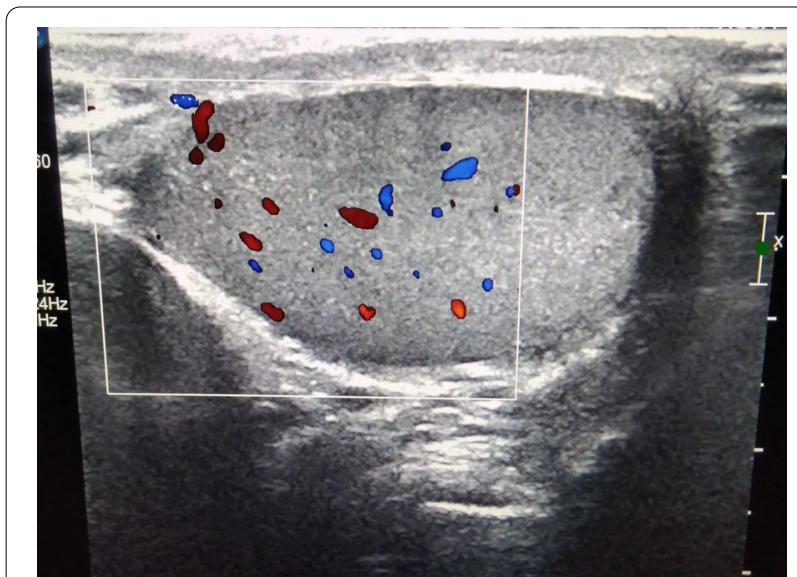

Fig. 1 USG of the scrotum shows normal right testis with normal echogenecity

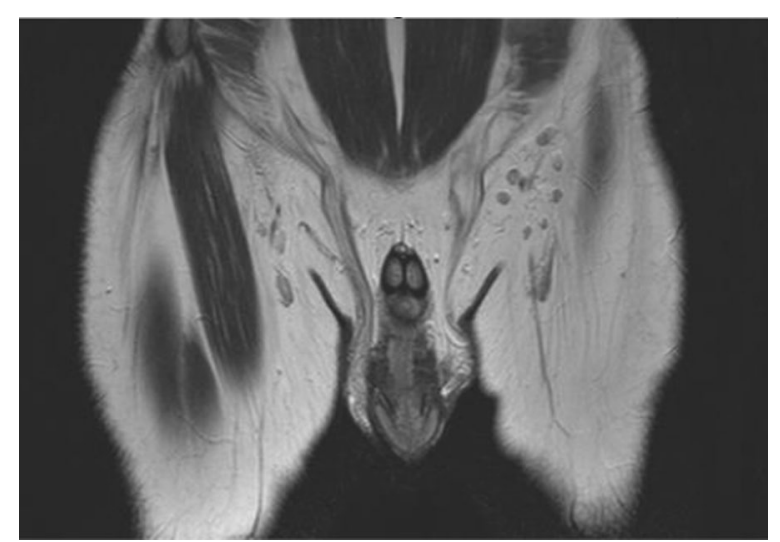

Fig. 2 MRI coronal T2 weighted image shows bilateral normal spermatic cord structures entering from the inguinal canal to the scrotum

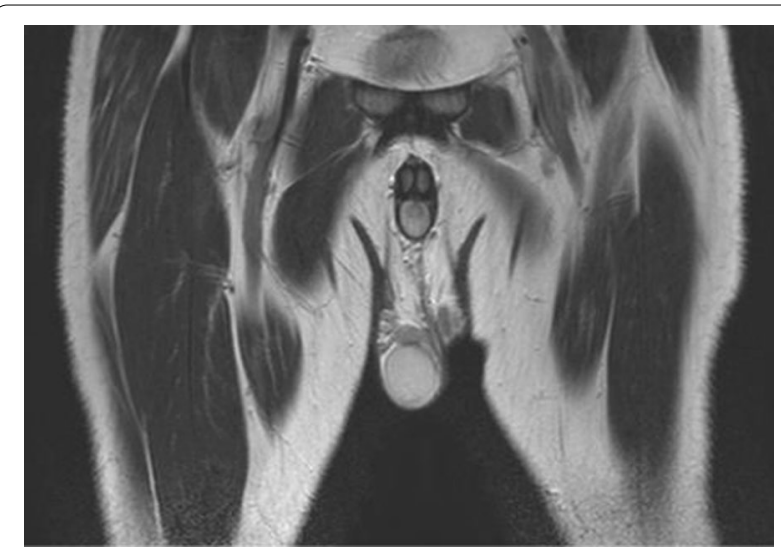

Fig. $3 \mathrm{MRI}$ coronal T2 weighted image shows right normal testis and small soft tissue nodule noted in the region of left testis and at the tip of left spermatic cord

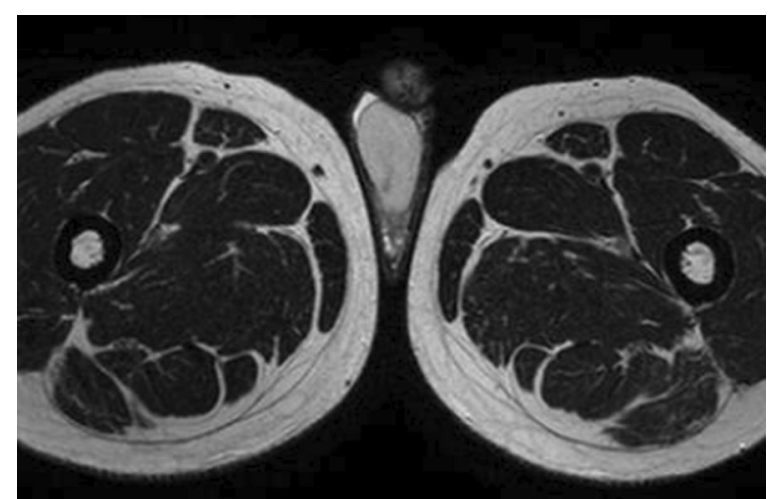

Fig. $4 \mathrm{MRl}$ axial T2 weighted image shows right normal testis in the right scrotal sac

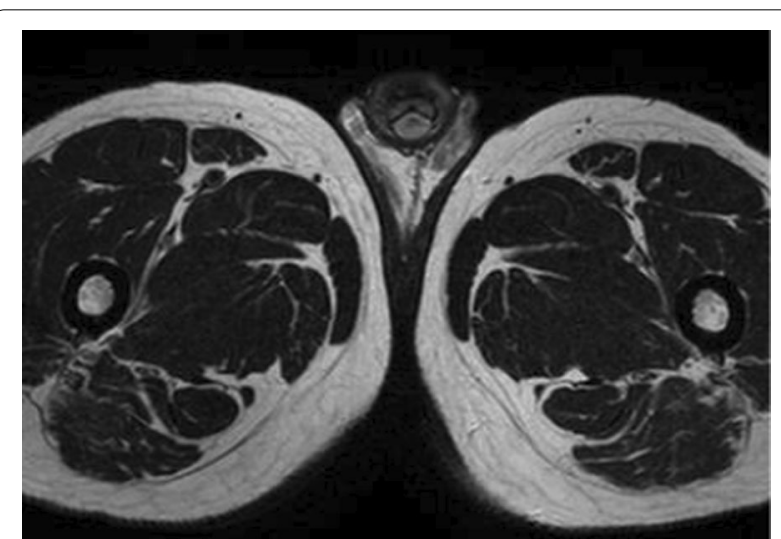

Fig. 5 MRI axial T2 weighted image small soft tissue nodule noted in the region of left testis and at the tip of left spermatic cord

after the formation of the normal testis [1]. The presence of a blind-ending spermatic cord is a piece of evidence that testis is formed during intrauterine life [2]. Young phenotypically normal male absence of unilateral testis is due to the consequence of perinatal or intrauterine testicular torsion [1]. It is a spectrum of disorders; clinical features are depending upon the stage of fetal or early neonatal life at which function of testicles ceases [3]. TRS is more common than testicular agenesis in the case of the non-palpable testis [3]. The usual protocol to followed in case of nonpalpable testis is given in the below flowchart. 


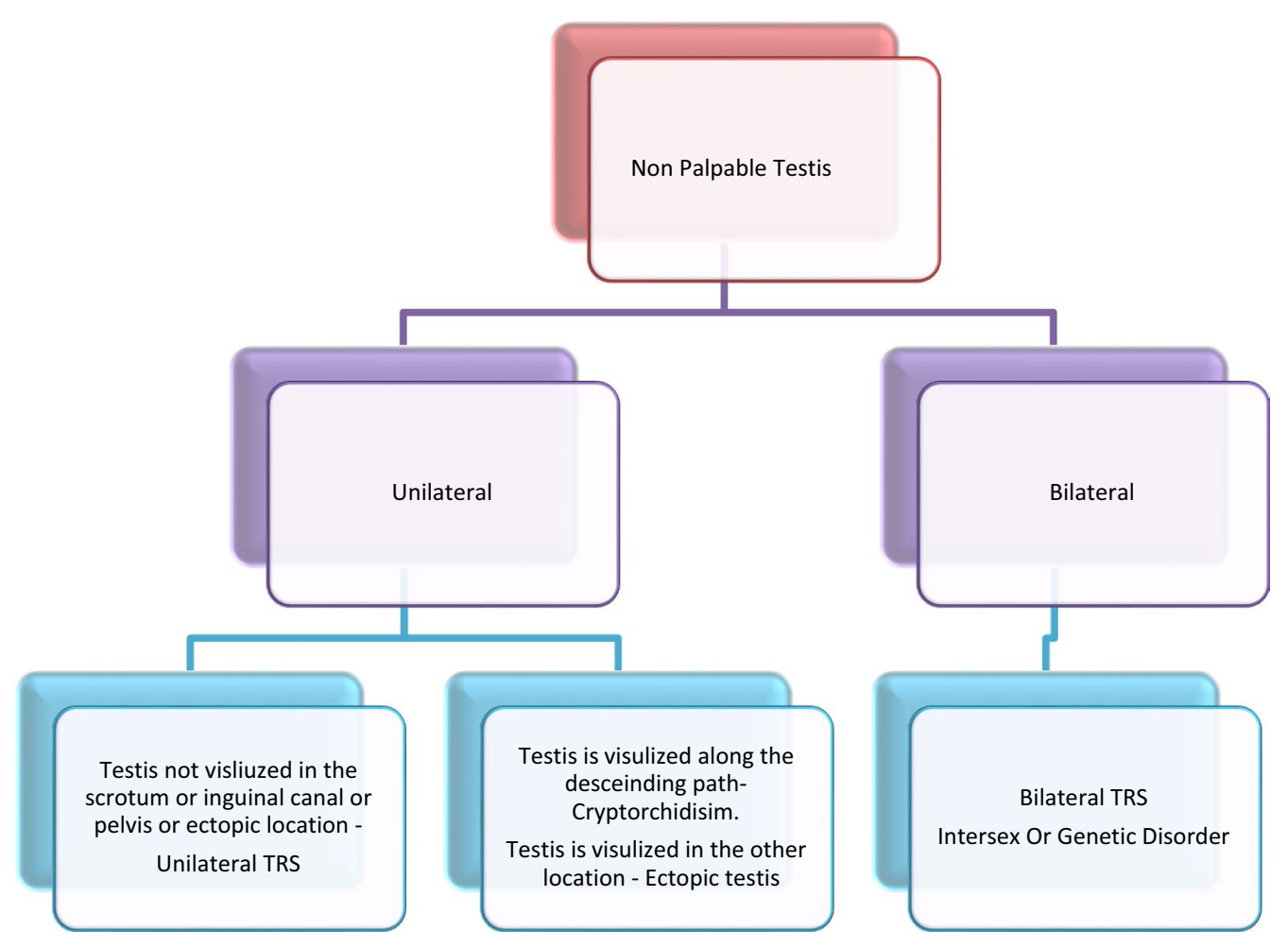

TRS is seen in 5\% of the cases of cryptorchidism [4]. Among 10-20\% nonpalpable testis in cryptorchidism, about $35-60 \%$ cases are TRS [1]. There may complete absence of testis, vas deferens, and epididymis (22.5\%), blindly-ending vas deferens (15\%), or blindly-ending vas deferens with blood vessels in the inguinal canal (67.5\%) [1].

The main postulated pathophysiology is due to late antenatal or perinatal torsion, vascular occlusion due to thrombosis, or endocrine disorder [5]. Incompletely undescended testis is more prone to torsion during the perinatal and fetal period than they normally descended testis [1]. The presence of hemosiderin-laden macrophages in the testis had supported the vascular insult as the cause of TRS $[6,7]$. The left side of the testis is more prone because of early descent of the left compared to the right $[3,6]$. Cryptorchidism is more common on the right, but Honore and Smith et al. found that the left testis was more susceptible to regression, and then with $68 \%$ of cases being left-sided [8]. It may be an anatomical arrangement of the left spermatic vein, draining into the left renal vein, which may predispose to kinking, due to an unusually mobile left kidney. As there is no venous anastomosis across the midline until after 16 weeks, leading to more common left testicular TRS.

It has also been reported with $\mathrm{Y}$ chromosome micro deletion [9]. Although most of the cases are sporadic in occurrence few cases also had been reported in the members of the same family $[10,11]$. Although TRS is usually unilateral, it can also be bilateral rarely associated with normal external genitalia (R1). The clinical presentation is classified based upon the age of presentation from early embryonic, late embryonic, early fetal, mid fetal, late fetal, and early neonatal [6]. Late presentation is the adult in the 4th decade is rarely described in the literature. Embryonic TRS is part of the partial (46XY) gonadal dysgenesis. Patients will exhibit the features of intersex or severe micropenis or even phonotypical females. The degree of masculinization of external and internal genitalia depends upon the duration of testicular function before regression. Missense mutation of the SF1 gene (V355M) is also reported recently in a boy with micropenis and TRS.

Intrauterine testicular descent occurs in two-phase, first during the 8-15 weeks and second during the 25-35 weeks. Various hormones are involved in the testicular descent are Human chorionic gonadotrophin, testosterone, and the protein hormone Insulin-Like 3 (INSL3).

TRS clinical diagnosis is based upon the clinically nonpalpable testis with blind-ending spermatic cord within the internal inguinal ring or in the retroperitoneum. The small fibrotic nodule is seen at the spermatic cord end which shows areas of fibrosis, dystrophic calcification hemosiderin deposition. Nodule shows viable germ cell or seminiferous tubule in $0-16 \%$ of the excised remnant [12]. 
The presence of germ cells can lead to the development of germ cell neoplasia in certain cases, but the absence of testicular tissue in many cases counterfeit the statement of germ cell neoplasia in the testicular remnant. Gross descriptive pathological features of TRS are several $\mathrm{cm}$ of spermatic cord with a small mass of firm, fibrotic tissue at one end. Elements of the vas deferens, spermatic artery, and venous plexuses are usually present [7].

Two essential criteria for TRS are (1) Visualizing the blind-ending spermatic vessels within the retro-peritoneum or visualizing spermatic vessels and vas deferens exiting a closed internal inguinal ring. (2) Testis is not palpated during examination under anesthesia.

Two different type of management exit, some urologist consider surgical exploration either via inguinal or scrotal approach with excision of testicular remnant, while other groups of surgeons consider conservative treatment [6].

The limitation of this case report is that, we had no surgical or pathological confirmation. Surgical exploration in case of TRS is a controversial issue.

\section{Conclusion}

What does this case report add to the existing knowledge?

TRS can even occur in adult upto 4th Decade.

Unilateral TRS in adult will not affect the sexual characteristics of the patient.

Germ Cell neoplasm is rare in TRS even in adults, although more common in cryptorchidiism.

Surgical exploration is not needed in all cases, especially in patients having normal physical and sexual characteristics.

\section{Abbreviations}

TRS: Testicular regression syndrome; USG: Ultra sonogram; MRI: Magnetic Resonance Imaging.

\section{Acknowledgements}

Not applicable.

\section{Authors' contributions}

MRKH had made substantial contributions to concept, design, acquisition, interpretation of data and in drafting the article. Author read and approved the final manuscript.

\section{Funding}

Not applicable.

\section{Availability of data and materials}

Data and materials are avalible.

\section{Declarations}

Ethical approval and consent for participation

Ethical approval not needed and since it's a retrospective case report study. Written consent had been obtained from the participant for participation.
Consent for publication

Written consent had been obtained.

\section{Competing interests}

The authors declare that they have no competing interests.

Received: 26 December 2021 Accepted: 31 January 2022

Published online: 07 February 2022

\section{References}

1. Hegarty P, Mushtaq I, Sebire N (2007) Natural history of testicular regression syndrome and consequences for clinical management. J Pediatr Urol 3(3):206-208

2. Diamond D, Caldamone A (1992) The value of laparoscopy for $106 \mathrm{impal}-$ pable testes relative to clinical presentation. J Urol 148(2 Part 2):632-634

3. Sharma D, Sagar D, Khurana D (2020) Testicular regression syndrome: a series of 22 cases at a tertiary care hospital. Trop J Pathol Microbiol 6(2):192-198

4. Spires S, Woolums C, Pulito A, Spires S (2000) Testicular regression syndrome. Arch Pathol Lab Med 124(5):694-698

5. Bar-Maor J, Groisman G, Lam M (1993) Antenatal torsion of the testes, a cause of vanishing testis syndrome. Pediatr Surg Int 8(3):236-238

6. Pirgon Ö, Dündar B (2012) Vanishing testes: a literature review. J Clin Res Pediatr Endocrinol 4(3):116-120

7. Smith N, Byard R, Bourne A (1991) Testicular regression syndrome? A pathological study of 77 cases. Histopathology 19(3):269-272

8. Honors L (1978) Unilateral anorchism Report of 11 cases with discussion of etiology and pathogenesis. Urology 11(3):251-254

9. Calogero A, Garofalo M, Barone N, De Palma A, Vicari E, Romeo R, Tumino $S$, D'Agata R (2001) Spontaneous regression over time of the germinal epithelium in a Y chromosome-microdeleted patient: case report. Hum Reprod 16(9):1845-1848

10. Marcantonio S, Fechner P, Migeon C, Perlman E, Berkovitz G (1994) Embryonic testicular regression sequence: a part of the clinical spectrum of 46, XY gonadal dysgenesis. Am J Med Genet 49(1):1-5

11. Wilson-Storey D (1996) Ante-natal testicular torsion: only one cause of the testicular regression syndrome? J Pediatr Surg 31(11):1600

12. Storm D, Redden T, Aguiar M, Wilkerson M, Jordan G, Sumfest J (2007) Histologic evaluation of the testicular remnant associated with the vanishing testes syndrome: is surgical management necessary? Urology 70(6):1204-1206

\section{Publisher's Note}

Springer Nature remains neutral with regard to jurisdictional claims in published maps and institutional affiliations.

\section{Submit your manuscript to a SpringerOpen ${ }^{\circ}$ journal and benefit from:}

- Convenient online submission

- Rigorous peer review

- Open access: articles freely available online

- High visibility within the field

Retaining the copyright to your article

Submit your next manuscript at springeropen.com 